\title{
Vibrational communication and mating behavior of the meadow spittlebug Philaenus spumarius
}

\author{
Sabina Avosani ${ }^{1,2, \star}$, Elissa Daher ${ }^{3,4}$, Pietro Franceschi², Marco Ciolli1,5, \\ Vincenzo Verrastro ${ }^{2}$, and Valerio Mazzoni ${ }^{2}$
}

1 DICAM Department of Civil, Environmental and Mechanical Engineering, University of Trento, Trento, Italy

2 Research and Innovation Centre, Fondazione Edmund Mach, San Michele all'Adige (TN), Italy

${ }^{3}$ CIHEAM - BARI International Centre for Advanced Mediterranean Agronomic Studies, Bari, Italy

4 Università degli Studi di Perugia, Perugia, Italy

5 C3A, Center Agriculture Food Environment, University of Trento, San Michele all'Adige (TN), Italy

* Corresponding author: sabina.avosani@unitn.it

With 4 figures and 8 tables

\begin{abstract}
Vibrational pest control techniques have been recently developed for several Hemiptera, suggesting that similar strategies could be applied to other species that emit vibrational signals. To evaluate the applicability of a control method for Philaenus spumarius, the vector of Xylella fastidiosa in olive orchards in Italy, we investigated its mating behavior and characterized the associated substrate-borne signals. The vibrational signals emitted by males and females were recorded with a laser vibrometer from the surface of a leaf. Male and female repertoires consisted each of three vibrational signals with distinct features. Pair formation begun with the calling signal of a receptive female and mating was accomplished when a vibrational duet was established and maintained until the male reached the female on the plant. Female calls and duets occurred only in trials conducted in September, while earlier in the season females emitted rejection signals to courting males. Intrasexual communication between males involved the emission of vibrational signals, whose role is still not clear. Playback trials with either a female or male calling signal elicited the emission of different vibrational signals by the tested males. Further experiments with playbacks are warranted to identify vibrational signals to be used for manipulating P. spumarius behavior and develop a future control method.
\end{abstract}

Keywords: pest control; behavioral manipulation; vibrational signals; Hemiptera: Aphrophoridae; Xylella fastidiosa

\section{Introduction}

Due to the increasing awareness about the deleterious impact of pesticides on human health and environment, there is an ongoing effort to design alternative methods for pest management in agriculture. In general, most strategies (i.e. push-and-pull and lure-and-kill tactics, mating disruption) involve the manipulation of the pest's behavior by means of different external stimuli. To be effective, these techniques must take into account the pest's physiological state and associated behaviors such as the process of pair formation (Foster and Harris 1997; Polajnar et al. 2015). In animals, mating is achieved through exchange of species-specific signals between a female and a male (Bailey 2003), which provides relevant information about identity, position and even quality of a potential mate (Endler 1992). It has been estimated that $92 \%$ of the insect species interacts by means of vibrational substrate-borne signals (Cocroft \& Rodriguez
2005) and in most Hemiptera these signals are crucial to accomplish mating (reviewed in Čokl \& Virant-Doberlet 2003; Polajnar et al. 2014). Typically, pair formation starts with the emission of an advertisement call by one of the two potential partners, to which a sexually mature male or female replies with its own signal. Establishment of a duet is critical to achieve mating in that it allows mate localization and copulation (Mazzoni et al. 2009b; De Groot et al. 2012). Interruption of the duet implies the interruption of the mating process. As such, in some insect species rival males evolved specific disruptive signals to prevent other males to mate (Booij 1982; Heady et al. 1986; Bailey et al. 2006; Miranda 2006). In the grapevine pest Scaphoideus titanus, a rival male can emit a masking signal that when transmitted as a playback in laboratory trials caused interruption of the duet (Mazzoni et al. 2009a, b). In further experiments conducted in semi-field trials, the continuous transmission of this signal into grapevine plants by electromagnetic 
transducers significantly reduced mating success of $S$. titanus (Eriksson et al. 2012; Polajnar et al. 2016). A similar method has been tested in laboratory (Gordon et al. 2017; Mazzoni et al. 2017a) and field (Krugner \& Gordon 2018) to interfere with the mating communication of the glassywinged sharpshooter, Homalodisca vitripennis, vector of the bacterium Xylella fastidiosa in California (Gordon et al. 2017), and the green grapevine leafhopper Empoasca vitis (Nieri \& Mazzoni 2018). Besides mating disruption, vibrational signals could be exploited as lures to attract the target insect into a trap. For example, this approach is driving the development of vibrational traps for the brown marmorated stink bug, Halyomorpha halys (Mazzoni et al. 2017b) and Asian citrus psyllid, Diaphorina citri (Hartman et al. 2017). In summary, the rapid and encouraging improvements in this field permit scientists to explore the use of vibrational signal playback as a novel tool for pest control.

The meadow spittlebug, Philaenus spumarius (Hemiptera: Aphrophoridae), is an abundant and worldwide spread species that occurs in almost all terrestrial habitats (Halkka \& Halkka 1990; Stewart \& Lees 1996). It's a univoltine insect that overwinters as egg and can feed on hundreds of plant species (Weaver \& King 1954; Cornara et al. 2018). Recently, this species became a threat for European agriculture because it is the main vector of $X$. fastidiosa in Southern Italy (Saponari et al. 2014; Cornara et al. 2019a), where the bacterium causes the Olive Quick Decline Syndrome (OQDS) (Saponari et al. 2017). Currently, X. fastidiosa has been found throughout the Mediterranean (Denance et al. 2017; Olmo et al. 2017). Therefore, an effective and sustainable management strategy for $P$. spumarius has become of high priority in the European Union. In the frame of a potential behavioral manipulation approach, knowledge of the pair formation process and the associated signals of $P$. spumarius are essential prerequisites to develop a control method (i.e. to repel, disrupt mating, attract) (Pedigo \& Rice 2014; Pertot et al. 2017). Several aspects of the biology (Weaver \& King 1954; Chmiel et al. 1979), genetics (Halkka et al. 1973; Maryańska-Nadachowska et al. 2012; Rodrigues et al. 2014), ecology (Santoiemma et al. 2019; Bodino et al. 2019) and feeding behavior (Cornara et al. 2018b; Cornara et al. 2019b; Markhaiser et al. 2020) of P. spumarius have been studied, but its sexual behavior has been poorly described. Despite the fact that egg maturation occurs only late in the summer due to an ovarian parapause (Witsack 1973), previous investigations have reported that multiple matings could occur soon after adult emergence in spring (Cornara et al. 2018; Morente et al. 2018). Although there is evidence of the emission of vibrational signals by $P$. spumarius males (Tishechkin 2003), their ethological function in conspecific interactions has not been investigated, while neither the emission of female's signals nor of duets have been reported.

The objective of this study was to characterize $P$. spumarius vibrational signals, describe their role in the pair formation process, and provide information for further research and development of vibration-based sustainable control techniques.

\section{Materials and methods}

\subsection{Insects}

Fourth and fifth instar nymphs of $P$. spumarius were collected in April 2017 and May 2018 from meadows in Riva Del Garda (Trentino, Italy). Host plants carrying spittle were cut and transported using a refrigerated bag to a glasshouse at the Fondazione Edmund Mach. Insects were then reared in mesh cages (Bugdorm-6620, 60×60×120 cm, MegaView Science Co., Ltd., Taiwan) under controlled conditions $\left(25 \pm 2{ }^{\circ} \mathrm{C}, \mathrm{L} 16\right.$ :D8, RH $\left.75 \pm 5 \%\right)$. Plants of Helianthus annus, Vicia faba, Trifolium repens and Rumex spp. were placed inside each cage as food source. Nymphs were checked daily and the newly emerged adults were removed and isolated by gender in order to obtain virgin individual to be used for the trials. The adults that emerged in the same day were placed on a plant of $H$. annus, which was enclosed by a cylindrical tube made of plastic net $(5 \mathrm{~cm}$ diameter $\times 15 \mathrm{~cm}$ height $)$. A nylon stocking on the top of the tube permitted air ventilation. Adult emergence ranged from the end of April and lasted until the $6^{\text {th }}$ of June.

\subsection{Recordings}

Recordings were carried out in a sound insulated chamber of the laboratory of Biotremology at Fondazione Edmund Mach (Italy), at a room temperature of $22 \pm 1{ }^{\circ} \mathrm{C}$ and $\mathrm{RH}$ of $65 \%$. The experimental arena was a Plexiglass cage $(30 \times 50 \times 30 \mathrm{~cm})$ with a circular opening on the top (diameter $6 \mathrm{~cm}$ ), which was placed on an anti-vibrational table (Astel s.a.s., Ivrea, Italy). A host plant (H. annus or $V$. faba, average height $12 \mathrm{~cm}, 2-4$ leaves) was placed into the cage. Insects were released on the plant after 15 minutes of acclimation in the room. Vibrational signals were recorded from a small piece of reflective tape attached on the lamina of the upper leaf by a laser Doppler vibrometer (Ometron VQ-500D-V), and digitized with Pulse (Brüel and Kjær Sound \& Vibration A/S, Nærum, 104 Denmark) at a $44.1 \mathrm{kHz}$ sample rate and 16-bit depth resolution through a data acquisition device (LAN XI type 3050-B-040, Brüel and Kjær Sound \& Vibration A/S, Nærum, Denmark), then stored onto a hard drive of a computer (HP, EliteBook 8460 p). Trials were recorded with a video-camera (mod. HTC-TM700, Panasonic, Japan) to associate the emission of vibrational signals with the corresponding behavior.

\subsection{Bioassays}

Three experiments of spontaneous behavior and three of playbacks to induce behavioral responses were conducted. In pair and trio trials, insects were released in a random order on the plant and their behavior was observed for 30 minutes or until copulation occurred. 


\subsubsection{Bioassay 1. Spontaneous behavior}

Single males and females. Males $(\mathrm{n}=105)$ and females $(\mathrm{n}=32)$ were singly placed on a $H$. annuus or $V$. faba plant and vibrational signals were recorded for 30 minutes to identify spontaneous calling signals. Because males emitted signals soon after adult molting, they were tested from the end of April until the end of June 2017 to study the daily pattern of calling activity. For statistical purposes, recordings were grouped in five 2-h periods from 08:00h to 19:00h. Calling activity of 21 males for each time-period was recorded. Single females were tested from the end of April to the end of June $2017(n=15)$ and from the end of July to the end of September $2017(\mathrm{n}=17)$. Further recordings of males $(\mathrm{n}=121)$ and females $(\mathrm{n}=201)$ were performed from August to October 2018 on a small plant of Vitis vinifera (height $10-15 \mathrm{~cm}$ ) in order to increase the number of observations during the most active period (in terms of mating communication) of the insect life cycle as emerged from the pairs' test (see results).

Pairs of a male and a female $(\mathrm{n}=188)$ were tested to describe the pair formation process. Trials were conducted from the end of April to the end of September 2017. For statistical analysis, recordings were grouped in the following 10 periods of 15 days: (1) from the end of April to mid-May $(n=17)$, (2) from mid-May to end of May $(n=20)$, (3) from the beginning of June to mid-June ( $\mathrm{n}=16)$, (4) from mid-June to the beginning of July $(\mathrm{n}=17)$, (5) from the beginning of July to mid-July ( $\mathrm{n}=18)$, (6) from mid-July to the beginning of August ( $\mathrm{n}=20)$, (7) from the beginning of August to midAugust ( $\mathrm{n}=19$ ), (8) from mid-August to the end of August $(\mathrm{n}=25)$, (9) from the beginning of September to mid-September $(\mathrm{n}=22)$ and (10) from mid-September to the end of September $(\mathrm{n}=14)$. Insects were released on a $H$. anпии or V. faba plant.

Trios $(\mathrm{n}=47)$ of two males and a female were released on a $H$. annuus or $V$. faba plant from mid-July to the end of August 2017. Behaviors and associated vibrational signals were recorded to evaluate intraspecific interactions and potential rivalry behaviors between males.

\subsubsection{Bioassay 2. Playback trials}

Males of $P$. spumarius were stimulated with playbacks of pre-recorded male and female calling signals (MCS and FCS, respectively, see results), to evaluate the possible role of these signals in the pair formation process. Playback signals were transmitted to a $V$. faba plant using a minishaker (Type 4810; Brüel and Kjær Sound \& Vibration A/S, Nærum, Denmark) in direct contact with a leaf via a conical rod. The background noise was filtered, and signals were modified using the audio software Adobe Audition 3.0 (Adobe Systems, Inc., San Jose, CA, USA), while the amplitude was adjusted to resemble the insect natural amplitude from previous recordings. In order to determine whether the transmission of the female signal could evoke different behaviors in males, we tested the female playback in two different periods of the P. spumarius adult season: October
2017 and June 2018. Conversely, the male signal was tested as playback only in June 2018 to ascertain possible effects in a period when only males emit vibrational signals, while females are silent (see results). Insect behaviors were followed using a video-camera and vibrational signals were recorded as described above.

October 2017. Three different female calling signals (FCS) were randomly transmitted to stimulate males $(n=42)$. The FCSs were composed of 20-25 chirps/signal, with a total duration of $6.5 \mathrm{~s}$ and a repetition time of $0.25-0.30 \mathrm{~s}$. A male was released on a leaf of the plant and after 3 minutes of acclimatization the playback was played seven times with one minute of interval between each signal. The test lasted for 10 minutes or until the insect jumped off.

June 2018. Males $(\mathrm{n}=40)$ were stimulated with the same three FCSs used in October 2017, while other males $(n=20)$ were tested with three male calling signal (MCS) consisting of 40 chirps/signal. The duration of each MCS was $48 \mathrm{~s}$, and the repetition time between chirps raged between $0.20 \mathrm{~s}$ and $0.25 \mathrm{~s}$. After 2 minutes of acclimatization, males were stimulated with either the female or the male playbacks, which were transmitted with 30 seconds of gap between consecutive signals. A third group of males $(n=20)$ was not stimulated as control.

\subsection{Terminology}

Vibrational signals were labelled according to their behavioral context.

Calling signals (or calls). Spontaneous emission of a signal by isolated insects (Booiji 1982).

Pulse. Unitary homogeneous parcel of sound of finite duration (Broughton 1963) and composed of a brief succession of sine waves (Alexander 1967).

Pulse train. Series of pulses arranged into temporally distinct groups.

Chirp. Continuous sound characterized by a fundamental frequency and a clear harmonic structure.

Syllable. Pulses and a chirp arranged into repeatable and temporally distinct groups, where a chirp is emitted after a brief train of pulses.

\subsection{Statistical analyses}

Spectral and temporal analyses of the recorded signals were performed with Raven 1.4 (The Cornell Lab of Ornithology, 151 Ithaca, NY) using Fast Fourier Transform (FFT) type Hann, with window length of 512 samples and $75 \%$ overlap. Recordings of males and females were used for analysis of temporal and spectral parameters of the vibrational signals; only signals recorded at a distance of $2-5 \mathrm{~cm}$ from the laser sticker were used in order to reduce the effect of different plants on signal transmission. Results are presented as means, ranges, and standard deviation (SD) together with the numbers of signals or elements within a signal analyzed for each individual $(\mathrm{N})$ and number of individuals (n) from which signals were obtained. The following parameters, 
when applicable, were measured for the signals: calling rate (intended as number of calling signals from the onset of the first one until the end of the trial), signaling latency (time from placement on the plant to the emission of the first vibrational signal), duration of the calls, duration and fundamental frequency (Ff) of the chirp, pulse/chirp repetition time (measured as the distance between the onsets of two consecutive sound elements), and duration and dominant frequency (Df) of the pulses. Additional parameters were measured for the Male Courtship Song (MCrS) (Table 2) and the male-female duet (Table 6), since those were composed of sections with a distinctive pattern. We analyzed only the duets that led to copulation (5 out of 6 duets). The number of signaling males in each period of the day was taken as measure of calling activity, and the G-test for contingency table (using log-likelihood ratios) after Williams' correction (Zar 1999) was used to compare calling activity between the periods of the day. The Wilcoxon-Mann-Whitney test (Zar 1999) was used to determine whether there was significant difference in the spectral and temporal features between the male and female signals. For playback trials, the percentage of males that emitted a signal after the stimulation were compared between trials in October 2017 and June 2018 as well as between stimulation and control, using chi-square in contingency Table $(2 \times 2$ and $2 \times 3$, respectively). The same test was used to determine whether playbacks had a repellent effect on insects by comparing the percentage of males that jumped off the plant after the stimulation between trials in October 2017 and June 2018 $(2 \times 2)$ and between control and stimulation trials $(2 \times 3)$. The type of signal evoked in the tested males was evaluated to associate each signal to a possible behavioral function. To ascertain that vibrational signals emitted by the tested males were due to the playbacks, the signaling latency of the stimulated group and the control was compared using a WilcoxonMann-Whitney test (Zar 1999). Data were analyzed using Past 3 (Hammer \& Harper, Øyvind Hammer, Natural History Museum, and University of Oslo).

A statistical analysis of the signals was performed using $\mathrm{R}$ ( $\mathrm{R}$ core team 2019) and visualized by ggplot (Wickham 2016) and tidyverse (Wickham 2017). Each measurement was characterized in terms of chirp duration, chirp fundamental frequency and repetition time between chirps. We did not perform any comparative analysis on the pulses since those were emitted mainly by males. To account for possible non-normality in the distribution of the parameters, the signals recorded from each individual were summarized by their median. An overall data inspection was performed to visualize the distribution of the log-transformed individualspecific signals $(\mathrm{Q} 2)$ in the three-dimensional space of the parameters by using the plot3D package (Soetaert 2017). The presence of a significant clustering among the signals was assessed by a permanova approach (Anderson 2008), implemented in the vegan package (Oksanen et al. 2019). A Wilcoxon-Mann-Whitney test (Zar 1999) was finally applied to compare male and female signals.

\section{Results}

\subsection{Bioassays 1. Spontaneous trials}

\subsubsection{Vibrational signals and mating behavior}

Vibrational signals of $P$. spumarius are composed of two different sound elements, which are defined as separate subunits: (i) a harmonic element ("chirp", fundamental frequency around $180.8 \pm 20.6 \mathrm{~Hz}$ ) and (ii) a pulse element ("pulse", dominant frequency $150 \pm 52.9 \mathrm{~Hz}$ ). The two subunits when emitted in sequence constitute a syllable, where a chirp follows a brief pulse train $(0.13 \pm 0.02 \mathrm{~s})$. The chirp is used by both males and females to compose their respective signals, while female pulses were rarely recorded ( $2 \%$ of the females of the pair trials). The male repertoire consists of three different types of vibrational signals: Male Calling Signal (MCS, Fig 1A), Male Courtship Signal (MCrS, Fig 1B), and Male-Male Signal (MMS, Fig 1C). Similarly, females emit three types of signals: Female Calling Signal (FCS, Fig 1D), Female Rejection Signal (FRjS, Fig 1E), and Female Response Signal (FRsS, Fig 1F). MCS (Fig. 1A) and FCS (Fig. 1D) are both composed of a train of short chirps. In addition, the MCS can be preceded by pulse trains or include syllables. The MCrS consists of chirp and pulses as well but with a more complex structure than the MCS (Table 1, Fig. 1A) since it can be divided in two sections, which are alternately emitted (Table 2, Fig. 1B). Section 1 consists of a long train of pulses with a rather variable repetition time (Table 2, Fig. 1B) and it is emitted while the male is walking on the plant. Section 2 occurs when the male is stationary and has a more regular pattern, being composed of a series of syllables of relatively constant duration and repetition time (Table 2, Fig. 1B). The MMS consists of a series of chirp elements with variable duration and repetition time (Table 3, Fig. 1C). Similarly, the FRjS consists in a continuous, long chirp element (Table 5, Fig. 1E) emitted alone or in trains with irregular repetition time. The FRsS is a short chirp emitted by a female in the time window between two consecutive male syllables during the duet (Table 6, Fig. 1F).

The signals were divided in three classes according to their structure: CS, the male and female calling signals, composed of regularly repeated short chirps; RS, rejection signals consisting of long and irregularly distributed chirps; CRS, male courtship signal. Plots of the analyzed parameters shows that the classes of signals have different chirp duration and repetition time, which, however, could not be used to clearly separate either calling or rejection signals between males and females (Fig. 2). The different properties of the three classes of signals are highlighted in the 3D plots (Fig. 3), which clearly show the partitioning of the parameter space. The RS signals could be clearly distinguished since the repetition time and the duration of the chirps were more distant from the values measured for the other two classes. Permanova shows that the signals were significantly different in the considered three parameter space (CRS-RS: $p=$ 

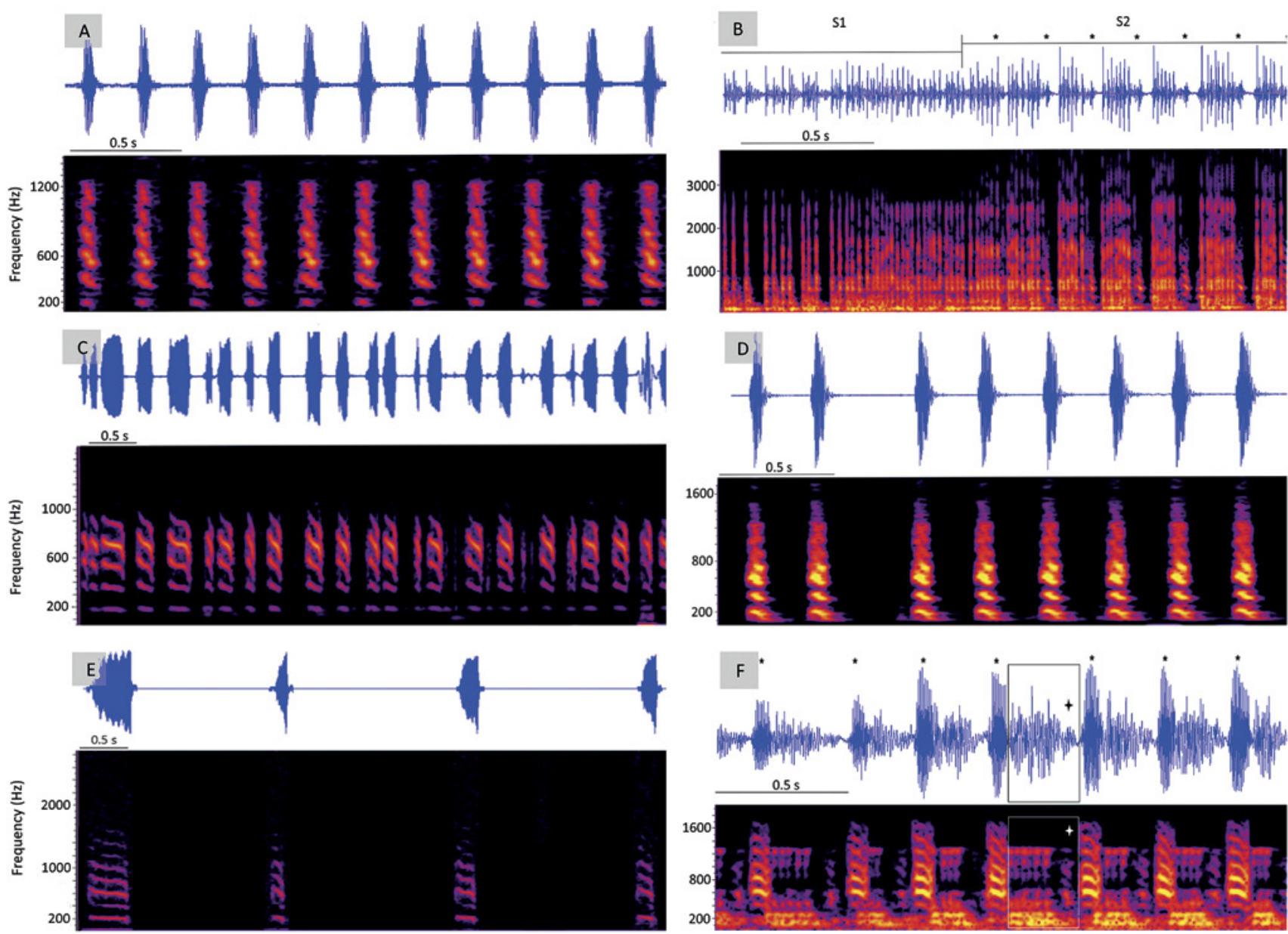

Fig. 1. Oscillograms (above) and spectrograms (below) of the vibrational signals of $P$. spumarius. A. Male Calling Signal (MCS) composed of chirp trains. B. Male Courtship Signal (MCrS), which is composed of two sections (S1 and S2). S1 consists of pulses, while S2 of pulses and chirps arranged in syllables. Asterisks indicate the chirps. C. Male-Male Signal (MMS). D. Female Calling Signal (FCS). E. Female Rejection Signal (FRjS). F. Portion of a male-female duet; the frame highlights the male contribution, the syllable, which is composed of a short pulse train followed by a harmonic element (chirp, pointed out by the star). The asterisks indicate the Female Response Signal (FRsS), also consisting of a chirp element.

Table 1. Temporal and spectral properties of the Male Calling Signal (MCS) of $P$. spumarius. $\mathrm{N}=$ number of measured elements; $\mathrm{n}$ = number of individuals; chirp = harmonic element; $\mathrm{Ff}$ = fundamental frequency; Df = dominant frequency.

\begin{tabular}{lccccc}
\hline Signal parameter & Mean \pm SD & Min. & Max. & n & N \\
\hline Calling Latency (s) & $774.71 \pm 493.18$ & 6.65 & 1767.43 & 23 & 1 \\
Call Rate (\%) & $4.13 \pm 2.97$ & 0.24 & 13.86 & 23 & See note below \\
Duration MCS (s) & $8.71 \pm 4.00$ & 3.27 & 19.74 & 26 & 4 \\
Duration chirp (s) & $0.063 \pm 0.007$ & 0.049 & 0.076 & 26 & 30 \\
Repetition time between chirps (s) & $0.270 \pm 0.031$ & 0.216 & 0.367 & 26 & 30 \\
Ff chirp (Hz) & $177.40 \pm 21.30$ & 140.27 & 217.67 & 26 & 30 \\
Repetition time between pulse trains (s) & $0.31 \pm 0.05$ & 0.23 & 0.36 & 14 & 5 \\
Duration pulse trains (s) & $0.07 \pm 0.02$ & 0.06 & 0.10 & 14 & 5 \\
Df pulse trains (Hz) & $161.37 \pm 34.37$ & 131.43 & 218.29 & 14 & 5 \\
\hline
\end{tabular}

note: for measuring the call rate, the number of signals emitted by each individual within the recording was used Means \pm standard deviation (SD), together with minimal and maximal measured values are shown. 
Table 2. Temporal and spectral properties of the Male Courtship Signal (MCrS) of $P$. spumarius. S1 and S2, sections 1 and section 2 of the MCrS; $N$ = number of measured elements; $n=$ number of individuals; chirp = harmonic element; $F f=$ fundamental frequency; Df $=$ dominant frequency.

\begin{tabular}{|c|c|c|c|c|c|}
\hline Signal parameter & Mean \pm SD & Min & Max & $\mathbf{n}$ & $\mathbf{N}$ \\
\hline Duration MCrS (s) & $601.48 \pm 524.44$ & 31.83 & 1371.64 & 8 & 1 \\
\hline Duration S1 (s) & $12.91 \pm 6.08$ & 5.74 & 23.76 & 8 & 5 \\
\hline Duration S2 (s) & $8.29 \pm 2.55$ & 5.95 & 13.43 & 8 & 5 \\
\hline Duration syllable (s) & $0.21 \pm 0.02$ & 0.20 & 0.25 & 8 & 30 \\
\hline Repetition time between syllables (s) & $0.26 \pm 0.02$ & 0.24 & 0.30 & 8 & 30 \\
\hline Duration chirp within the syllable (s) & $0.06 \pm 0.01$ & 0.05 & 0.073 & 8 & 30 \\
\hline Ff chirp within the syllable (Hz) & $197.87 \pm 12.01$ & 181.33 & 216.27 & 8 & 30 \\
\hline Duration pulse trains in S1 (s) & $4.46 \pm 12.17$ & 0.12 & 34.59 & 8 & 30 \\
\hline Duration pulse trains in S2 (s) & $0.13 \pm 0.02$ & 0.10 & 0.17 & 8 & 30 \\
\hline Df pulse trains in $\mathrm{S} 1(\mathrm{~Hz})$ & $147.87 \pm 66.09$ & 82.67 & 277.33 & 8 & 30 \\
\hline Df pulse trains in S2 $(\mathrm{Hz})$ & $144 \pm 63.10$ & 96 & 276.27 & 8 & 30 \\
\hline Number of S1 & $26.50 \pm 19.76$ & 7 & 56 & 8 & 1 \\
\hline Number of S2 & $25.88 \pm 19.52$ & 8 & 55 & 8 & 1 \\
\hline
\end{tabular}

Table 3. Temporal and spectral properties of the Male-Male Signal (MMS) of $P$. spumarius. $\mathrm{N}=$ number of measured elements; $\mathrm{n}=$ number of individuals; chirp = harmonic element; $\mathrm{Ff}=$ fundamental frequency.

\begin{tabular}{|c|c|c|c|c|c|}
\hline Signal parameter & Mean \pm SD & Min. & Max. & $\mathbf{n}$ & $\mathbf{N}$ \\
\hline Duration chirp (s) & $0.14 \pm 0.01$ & 0.12 & 0.16 & 8 & 30 \\
\hline Repetition time between chirps (s) & $0.50 \pm 0.25$ & 0.28 & 0.95 & 8 & 30 \\
\hline Ff chirp $(\mathrm{Hz})$ & $180.97 \pm 20.80$ & 153.07 & 206.67 & 8 & 30 \\
\hline
\end{tabular}

0.001) (CS-CRS: $\mathrm{p}=0.003)(\mathrm{CS}-\mathrm{RS}: \mathrm{p}=0.001)$. Moreover, male and female calling signals are significantly different in chirp duration $(\mathrm{dbl}=796$, Wilcoxon rank, two sided $\mathrm{p}<0.001)$ and in repetition time between chirps $(\mathrm{dbl}=730$, Wilcoxon rank two sided $\mathrm{p}<0.001)$, while the fundamental frequencies are rather similar $(\mathrm{dbl}=222$, Wilcoxon rank, two sided $p=1$ ). The male and female rejection signals (the MMS and the FRjS, respectively) are significantly different in the repetition time between chirps (Wilcoxon rank, $\mathrm{dbl}=$ 45 , two sided $\mathrm{p}<0.001$ ), while the chirp duration (Wilcoxon rank, $\mathrm{dbl}=37.5$, two sided $\mathrm{p}=1$ ) and the fundamental frequency (Wilcoxon rank, $\mathrm{dbl}=33.5$, two sided $\mathrm{p}=1$ ) are similar between the signals. The Wilcoxon-Mann-Whitney test confirms the significant differences in the spectral and temporal features between the calling and rejection signals (Table 8).

\subsubsection{Single trials}

Both males and females of $P$. spumarius emitted vibrational signals spontaneously within 30 minutes from placement on the plant. Among the males tested from April to the end of June 2017, 22\% ( $n=105)$ emitted at least one MCS, which was never recorded from individuals younger than four days from adult molting. The MCS was usually composed of chirps only (Table 1, Fig. 1A), except for eight males who emitted also short $(0.07 \pm 0.02 \mathrm{~s})$ trains of pulses either before or within the MCS. The chirp repetition time was relatively constant (Table 1 ), while the calling latency was rather variable (Table 1) and there was not a significant difference in male calling activity between different periods of the day ( $\mathrm{G}$ test; $\mathrm{G}=3.53$, $\mathrm{df}=4, \mathrm{p}=0.47$ ). In some cases, males $(56.5 \%, n=23)$ jumped from the point of signal emission after the MCS, and the number of calling signals varied greatly among different individuals $(4.8 \pm 5.5$, minimum $=1$; maximum $=23$ ).

None of the females tested during the first period of trials from April to the end of June $(n=15)$ emitted a signal, while $52.9 \%$ of the females tested in September $(n=17)$ emitted a Female Calling Signal (FCS), which consisted in a chirp train with relatively constant repetition time (Table 4, Fig. 1D). Females called from different parts of the leaf, and the number of FCS varied among different individuals $(9.41 \pm 5.8$; minimum $=3$; maximum $=17)$. In contrast with males, females did not leave the plant after calling.

\subsubsection{Pair trials}

Pair formation started with the emission of the FCS, which elicited $(n=6)$ emission of $\mathrm{MCrS}$ and thus, the onset of a 

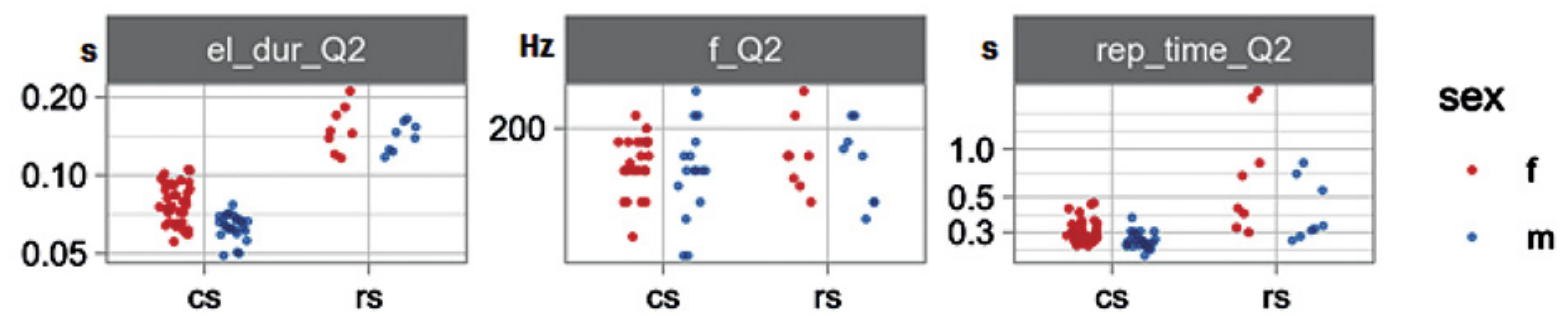

Fig. 2. Distribution of the analyzed parameters for calling and rejection signals. Each point represents the median of the signals measured for each individual, different colors (red and blue) indicate females and males, respectively. El_dur = chirp duration; $f=$ chirp fundamental frequency; rep_time = chirp repetition time; $c s=$ calling signals; $r s=$ rejection signals.

CRS

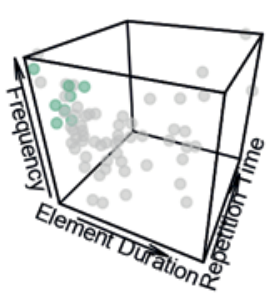

RS

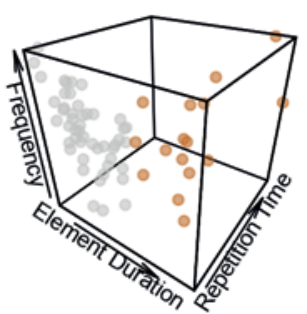

CS

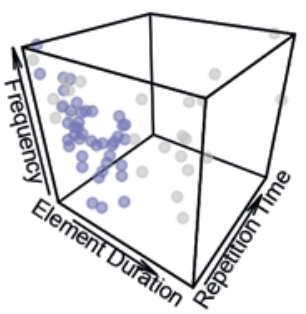

Fig. 3. 3D plots representing the distribution of the three class of signals in relation to the others. Classes are defined as: courtship (CRS), rejection (RS), and calling (CS). Element duration = duration of chirps; $C R S$ = male courtship signal; $R S=$ female rejection signals and male-male signal; $\mathrm{CS}=$ female and male calling signals (MCS and FCS).

male-female duet (Table 6, Fig. 1F). The latter was established when a female replied to the male with emission of FRsS in the time window between two consecutive male syllables within the $\mathrm{S} 2$ of the MCrS, although occasional FRsS occurred also during S1. The female response triggered the search of the male, which continued to emit the MCrS also while walking. The exchange of signals led to the localization of the stationary female by the male and, eventually, to copulation (mating success of duetting males: 83\%). Duets were observed only in September (Table 7), while prior to this period, females were refractory to mating by emitting a rejection signal (FRjS) to an approaching male that tried to mount her. In contrast, a duetting female neither rejected a male nor expressed acceptance with emission of a vibrational signal. During mating, which lasted for 3-4 hours, both insects emitted copulatory vibrational signals consisting of randomly arranged and overlapped chirps. Few males (6 out of 188 tested) achieved mating without the emission of any vibrational signal but directly mounting on the female, which struggled to escape and jumped off the plant with the male attached. These forced copulations lasted for hours and occurred occasionally in our trials, throughout the season even when females were not acoustically active. Contrarily to the FCS, the MCS was emitted with slightly variable frequency throughout the experimental period (Table 7), while the MCrS was recorded starting from the $6^{\text {th }}$ period (Table 7).

\subsubsection{Trio trials}

MCS either with $(14.9 \%, \mathrm{n}=47)$ or without pulses $(6.4 \%$, $\mathrm{n}=47)$ and $\mathrm{MCrS}(4.3 \%, \mathrm{n}=47)$ were recorded during trio trials as well. However, only the males of the trio trials emitted a Male-Male Signal (MMS), which was observed after interaction between the two males $(17 \%, \mathrm{n}=47)$. In particular, MMS was mostly emitted after physical contact, after emission of MCS (with or without pulses), or after emission of MCrS by the other male in close proximity. The MMS could either partially $(50 \%, n=8)$ or completely $(50 \%, n=8)$ overlap the signals emitted by the other male, until one of them ceased to reply or, in one case, jumped off the plant. In two cases, one of the males mounted on the other. Similar to pair trials, when a male physically interacted with a female the latter emitted the FRjS $(21.3 \%, n=47)$, then ran away and/or jumped off the plant $(14.9 \%, n=47)$. The FRjS could be evoked by the MCrS of a relatively nearby male, whereas neither a FCS nor a duet were ever observed.

Audio files of the MCS (train of chirps), MCS (pulses and chirps), MMS, FCS, FRjS and duet are provided as 
Table 4. Temporal and spectral properties of the Female Calling Signal (FCS) of $P$. spumarius. $\mathrm{N}=$ number of measured elements; $\mathrm{n}=$ number of individuals; chirp = harmonic element; $\mathrm{Ff}=$ fundamental frequency.

\begin{tabular}{|c|c|c|c|c|c|}
\hline Signal parameter & Mean \pm SD & Min. & Max. & $\mathbf{n}$ & $\mathbf{N}$ \\
\hline Calling Latency (s) & $183.39 \pm 213.15$ & 0.128 & 870.799 & 71 & 1 \\
\hline Duration FCS (s) & $2.89 \pm 1.88$ & 2.34 & 9.42 & 36 & 20 \\
\hline Duration chirp (s) & $0.079 \pm 0.014$ & 0.056 & 0.106 & 36 & 30 \\
\hline Repetition time between chirps (s) & $0.313 \pm 0.055$ & 0.252 & 0.478 & 36 & 30 \\
\hline Ff chirp $(\mathrm{Hz})$ & $180.81 \pm 13.82$ & 150.93 & 182.13 & 36 & 30 \\
\hline
\end{tabular}

Table 5. Temporal and spectral properties of the Female Rejection Signal (FRjS) of $P$. spumarius. $\mathrm{N}=$ number of measured elements; $\mathrm{n}=$ number of individuals; chirp = harmonic element; $\mathrm{Ff}=$ fundamental frequency.

\begin{tabular}{|c|c|c|c|c|c|}
\hline Signal parameter & Mean \pm SD & Min. & Max & $\mathbf{n}$ & $\mathbf{N}$ \\
\hline Duration chirp (s) & $0.16 \pm 0.04$ & 0.12 & 0.25 & 8 & 30 \\
\hline Repetition time between chirps(s) & $1.05 \pm 0.67$ & 0.33 & 2 & 8 & 30 \\
\hline Ff chirp $(\mathrm{Hz})$ & $185.76 \pm 18.14$ & 167 & 222 & 8 & 30 \\
\hline
\end{tabular}

Table 6. Temporal and spectral properties of the vibrational signals emitted during the male-female duet. S1 and S2, sections 1 and 2 of the Male Courtship Signal; $N=$ number of measured elements; $n=$ number of individuals; chirp = harmonic element; $\mathrm{Ff}=$ fundamental frequency; $\mathrm{Df}=$ Dominant frequency.

\begin{tabular}{|c|c|c|c|c|c|}
\hline Signal parameter & Mean \pm SD & Min. & Max. & $\mathbf{n}$ & $\mathbf{N}$ \\
\hline Duration duet (s) & $245.68 \pm 197.46$ & 2.83 & 483.61 & 6 & 1 \\
\hline Duration S1 (s) & $9.05 \pm 2.48$ & 6.23 & 12.07 & 5 & 5 \\
\hline Duration S2 (s) & $7.04 \pm 1.31$ & 5.90 & 9.17 & 5 & 5 \\
\hline Duration syllables (s) & $0.19 \pm 0.03$ & 0.16 & 0.22 & 5 & 30 \\
\hline Duration pulse trains in $\mathrm{S} 2(\mathrm{~s})$ & $0.16 \pm 0.10$ & 0.08 & 0.34 & 5 & 30 \\
\hline Repetition time syllables (s) & $0.25 \pm 0.01$ & 0.24 & 0.26 & 5 & 30 \\
\hline Number of syllables/S2 & $32.41 \pm 6.36$ & 25.00 & 39.00 & 5 & 5 \\
\hline Ff chirp within the syllable $(\mathrm{Hz})$ & $193.87 \pm 9.41$ & 184 & 206 & 5 & 30 \\
\hline Df pulse trains $\mathrm{S} 2(\mathrm{~Hz})$ & $112.75 \pm 31.40$ & 84.27 & 165.87 & 5 & 30 \\
\hline Df pulse trains within the syllable in $\mathrm{S} 2(\mathrm{~Hz})$ & $108.80 \pm 14.30$ & 95.47 & 130.67 & 5 & 30 \\
\hline Df pulse trains in $\mathrm{S} 1(\mathrm{~Hz})$ & $643.72 \pm 818.23$ & 0.10 & $1,922.99$ & 5 & 30 \\
\hline Duration Female Response Signal (s) & $0.08 \pm 0.01$ & 0.07 & 0.09 & 5 & 30 \\
\hline Ff Female Response Signal (Hz) & $167.36 \pm 10.20$ & 158.93 & 182.40 & 5 & 30 \\
\hline Female response latency (s) & $70.13 \pm 91.21$ & 0.00 & 223.24 & 7 & 1 \\
\hline Female response rate in $\mathrm{S} 1(\%)$ & $0.14 \pm 0.17$ & 0.00 & 0.44 & 7 & 1 \\
\hline Female response rate in $\mathrm{S} 2(\%)$ & $0.71 \pm 0.20$ & 0.43 & 0.95 & 7 & 1 \\
\hline Number of S1 & $23.2 \pm 14.08$ & 7 & 45 & 5 & all \\
\hline Number of S2 & $22.6 \pm 14.47$ & 6 & 45 & 5 & all \\
\hline
\end{tabular}

supplementary material in Online Resources 1, 2, 3, 4, 5, and 6 , respectively.

\subsection{Bioassays 2: Stimulation trials with playbacks}

Males stimulated with playbacks responded by emitting different vibrational signals $(n=42,28.6 \%$, Fig. 4). The number of signaling males after the transmission of the female playback (Fig. 4) was numerically lower in June 2018 ( $\mathrm{n}=40$, $5.8 \%$ ) than in October 2017, but there was no significant difference between the two periods (Chi-squared test; $X^{2}=$ 3.220 , df $=1, p=0.073)$. In absence of any external vibrational stimulus, $20 \%$ of the males $(n=20)$ emitted at least one MCS (Fig. 4).

Comparing the percentages of signaling males tested in the two periods, we did not find a statistical difference 

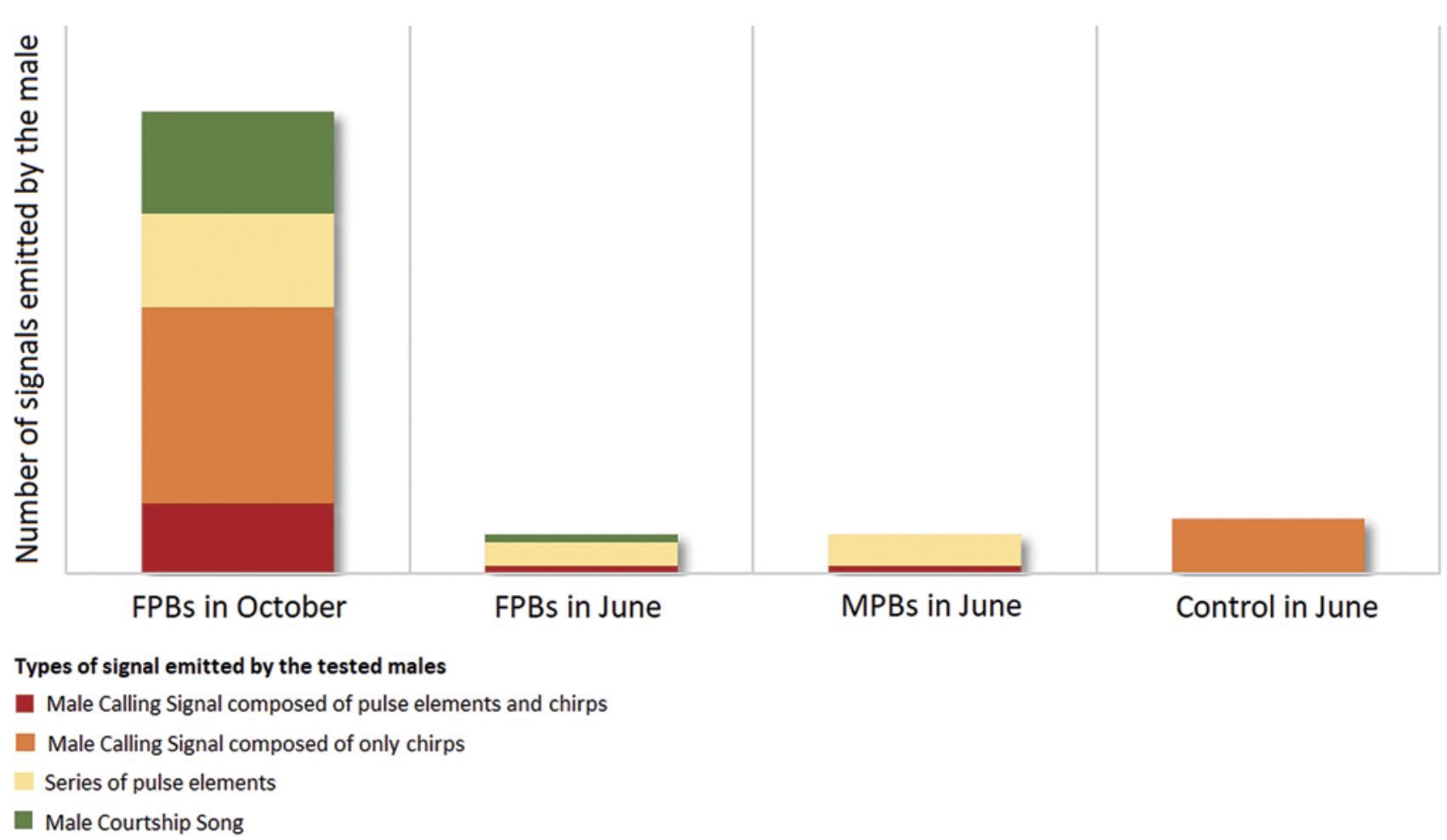

Fig. 4. Type of signals emitted by the males tested in the playback trials. FPBs = Female Playbacks; MPBs = Male Playbacks; chirp $=$ harmonic element.

between the control group and the groups stimulated with playbacks of male or female signals (Chi-squared test; $X^{2}$ $=0.949, \mathrm{df}=2, \mathrm{p}=0.622$ ). Similarly, the percentages of males that jumped off the plant did not significantly differ between the stimulated groups in October 2017 and June 2018 (Chi-squared test; $X^{2}=2.052$, $\mathrm{df}=1, \mathrm{p}=0.152$ ) or between the stimulated and the control groups (Chi-squared test; $\left.X^{2}=0.739, \mathrm{df}=2, \mathrm{p}=0.691\right)$. Nonetheless, the number of jumping males in the control $(\mathrm{n}=20 ; 25 \%)$ was numerically higher than the group stimulated either with the female $(\mathrm{n}=42$ in October; $7.1 \%$ and $\mathrm{n}=40$ in June; $5.8 \%)$ and the male playbacks $(\mathrm{n}=20 ; 15 \%)$. There was statistical difference in the signaling latency between the stimulated and the control groups (Wilcoxon-Mann-Whitney test: $\mathrm{p}=0.0021$ ).

\section{Discussion}

The present study provides the first detailed description of the vibrational substrate-borne signals produced by $P$. spumarius and the associated mating behavior. Similar to other species in Hemiptera (Čokl and Virant-Doberlet 2003), inter-sexual communication relies on vibrational signals and, overall, $P$. spumarius mating behavior resembled the general scheme known for other Auchenorrhyncha, albeit with some differences.

\subsection{Phenology}

In Auchenorrhyncha, females typically need more time than males to reach reproductive maturity (Krugner 2010; Mazzoni et al. 2009b). Accordingly, P. spumarius males tried to accomplish mating throughout the season in laboratory conditions, while females called and then established duets with males only from September. Because egg maturation begins in September and continues until the female dies (Weaver and King 1954), calls and vibrational duets likely occur when the female carries mature eggs in the ovaries. In fact, female calling activity is an indicator of reproductive maturity and receptiveness to mating (Hoch \& Howarth 1993), and a similar relationship between presence of mature eggs and female calling has been suggested in H. vitripennis (Nieri et al. 2017), where the pre-oviposition period ranged from 9 to 285 days (Krugner 2010). $P$. spumarius females called in September even if we reared the insects under controlled conditions (temperature and photoperiod), and this fact is in strong disagreement with the literature (Witsack 1973; Morente et al. 2018). Since we neither dissected the females nor performed oviposition trials, we could not evaluate whether the ovarian parapause was broken. Nevertheless, photoperiod is potentially not the only factor that drives the development of $P$. spumarius ovaries, thus further trials should be addressed to unveil which factors promote ovarian development and the potential 
Table 7. Signals emitted by either a female or a male of $P$. spumarius during the pair trials (at least one signal per individual). FCS = Female Calling Signal, FRjS = Female Rejection Signal; MCS = Male Calling Signal; MCrS = Male Courtship Signal; chirp = harmonic element; $n$ = number of pairs tested for each period; (1) end of April to mid-May, (2) mid-May to end of May, (3) beginning of June to mid-June, (4) mid-June to beginning of July, (5) beginning of July to mid-July, (6) mid-July to begging of August, (7) beginning of August to mid-August, (8) mid-August to end of August, (9) beginning of September to mid-September, (10) mid- September to end of September.

\begin{tabular}{lccccccc}
\hline Period & Females emitting at least one & \multicolumn{2}{c}{ Males emitting at least one } & \multicolumn{2}{c}{ Onset of a } \\
& N & $\begin{array}{c}\text { FCS } \\
\mathbf{( \% )}\end{array}$ & $\begin{array}{c}\text { FRjS } \\
\text { (\%) }\end{array}$ & $\begin{array}{c}\text { MCS (\%) } \\
\text { (only chirps) }\end{array}$ & $\begin{array}{c}\text { MCS (\%) } \\
\text { (chirp+pulses) }\end{array}$ & $\begin{array}{c}\text { MCrS } \\
\text { (\%) }\end{array}$ & $\begin{array}{c}\text { duet } \\
\text { (\%) }\end{array}$ \\
\hline 1 & 17 & 0 & 17.6 & 11.8 & 11.8 & 0 & 0 \\
2 & 20 & 0 & 30 & 15 & 10 & 0 & 0 \\
3 & 16 & 0 & 6.3 & 0 & 0 & 0 & 0 \\
4 & 17 & 0 & 17.6 & 5.9 & 5.9 & 0 & 0 \\
5 & 18 & 0 & 11.1 & 16.7 & 5.6 & 0 & 0 \\
6 & 20 & 0 & 30 & 5 & 5 & 20 & 0 \\
7 & 19 & 0 & 0 & 15.8 & 10.5 & 0 & 0 \\
8 & 25 & 0 & 4 & 12 & 12 & 16 & 0 \\
9 & 22 & 18.2 & 0 & 22.7 & 4.5 & 9.1 & 9.1 \\
10 & 14 & 28.6 & 0 & 0 & 7.1 & 28.6 & 28.6 \\
\hline
\end{tabular}

Table 8. Temporal and spectral parameters of different male and female signals after a Wilcoxon-Mann-Whitney $U$ test. FCS = Female Calling Signal, FrjS = Female Rejection Signal; MCS = Male Calling Signal; MMS = Male-Male Signal; chirp = harmonic element; $F f=$ fundamental frequency; $n=$ number of individuals. Significance $(p<0.05)$ shown in bold.

\begin{tabular}{llccc}
\hline Comparison & Parameter & U & n & p \\
\hline FCS vs FRjS & Chirp duration (s) & 26 & 8 & NS \\
MCS vs MMS & Chirp duration (s) & 0 & 8 & $<\mathbf{0 . 0 0 1}$ \\
FCS vs FRjS & Chirp repetition time (s) & 8 & 8 & $\mathbf{0 . 0 1 1}$ \\
MCS vs MMS & Chirp repetition time (s) & 6 & 8 & $\mathbf{0 . 0 0 4}$ \\
FCS vs FRjS & Chirp Ff (Hz) & 8 & 8 & $\mathbf{0 . 0 1 0}$ \\
MCS vs MMS & Chirp Ff (Hz) & 18 & 8 & NS \\
\hline
\end{tabular}

association between the presence of eggs and female calling activity.

In the field $P$. spumarius mates soon after adult molting (Yurtsever 2001), and in our trials some males silently approached and mounted the female. This behavior could give a reproductive advantage to the male if the female preserves the sperm until egg maturation occurs, considering that the spermatheca allows a delayed fertilization (Robertson \& Gibbs 1937). Since polyandry has been reported in P. spumarius (Yurstever 2001), the female could potentially fertilize eggs using newly acquired sperm from additional mates. In particular, she could use the sperm of the male that engaged a duet with her and eventually localized her. In this perspective, the sperm acquired after a forced copulation does not give a genetic contribution, if the female uses the sperm of the last mate. According to this, last-male sperm precedence is a widespread reproductive strategy among insects (Gwynne 1987) and has been proposed for $P$. spumarius (Yurstsever 2001).

\subsection{Pair formation process}

During the initial phase of mate finding, the female calling signal (FCS) provided the indication of the availability of a reproductive mature female and triggered emission of the MCrS. The rapid inversion of female leading/male replying roles resulted in males guiding subsequent duets to locate the female, whose signal was reduced to a short chirp (the female response signal, FRsS). Mating success presumably depended on the male ability to maintain the female acceptance and to find her on the plant, while the decreased signaling activity of the female could be a strategy to save energy and/or reduce risks of predators eavesdropping (Virant-Doberlet et al. 2014). A similar behavior was reported in $H$. vitripennis (Nieri et al. 2017) and in the planthopper Hyalesthes obsoletus, where females call to form a duet and then males lead the following phases of communication (Mazzoni et al. 2010). During mate identification and localization, males usually tend to optimize the energy consumption (Kuhelj et al. 2015); therefore, due to 
the degradation of the spectral characteristics of the signals along plants, which act as frequency filters (Michelsen et al. 1982), an important part of the mate choice likely occurs when the male is close enough to the female. Accordingly, in many Hemiptera, the male emits a specific and likely more complex signal when he gets enough close to the female to increase her acceptance (i.e, Mazzoni et al. 2010; Polajnar et al 2014). On the other hand, P. spumarius males use a specific courtship signal, the MCrS, unvaried throughout the duet until copulation. Since it consists of alternately emitted sections with different structures, these could have different roles and require a different involvement of resources from the male. In particular, the pulse train of the first section could serve to maintain the female interest during localization, while the female replies in the second section could provide the directional cues to the male while he is stationary. The second section is probably the most energetically costly subpart of the male repertoire, suggesting that mate choice could occur during this phase. Moreover, this could be the communication phase more susceptible to external interference by playing back disruptive signals (i.e. the FRjS and the MMS) with the aim to decrease the receptivity or even mask the female signals.

\subsection{Vibrational communication and role of the signals}

Chirps and pulses are emitted in a stereotyped sequence to produce a repertoire of signals, which are associated with different behavioral contexts. Series of short chirps underlie advertisement signals such as the MCS and the FCS, while longer chirps constitute a class of signals (FRjS and MMS) that denote distress after interaction with a conspecific. The FRjS, for instance, was emitted by females to reject a male after physical contact or during male signaling, a behavior also observed in the stink bug Nezara viridula (Čokl et al. 2000) and in the leafhopper Scaphoideus titanus (Mazzoni et al. 2009a). Because MMS consisted of an exchange of signals between interacting males, its biological meaning could be of dominance, interference towards other males, expression of distress, or defining territory. In this regard, rivalry signals are present in the repertoire of many Auchenorrhyncha and their function is to disturb or mask male-female duets (Booij 1982). For example, in the treehopper Ennya chrisura (Hemiptera: Membracidae) a rival signal is emitted by both competitors when in close proximity (Miranda 2006), while in S. titanus males can emit a disturbance noise that aims at masking the female reply (Mazzoni et al. 2009a). Further trials are therefore needed to unveil the role of this signal in male-male interactions.

The biological meaning of the MCS remained unclear as well. This signal was recorded in almost all the recording periods throughout the season, but it neither elicited the emission of a FCS nor took part in the duet. We excluded that the purpose was to chase away a rival male because the playback of the MCS did not have a repellent effect on the tested males. Despite having spectral characteristics similar to FCS, a potential role of female mimicry was also excluded due to a different temporal pattern. Thus, while the FCS is clearly associated with mating and female receptivity, the MCS could be a territoriality signal that advertises the sender in terms of actual presence and, possibly, quality. In H. obsoletus, the male emits a calling signal with temporal and spectral features similar to the female signal (Mazzoni et al. 2010), but the behavioral meaning for this signal remains unclear. However, the MCS of P. spumarius (when composed of chirps and pulses) partially resembles the MCrS, therefore it could be either a form of "preparatory" courtship signal or potentially trigger the emission of a FCS from a distant female. Interestingly, the presence of a silent female was sufficient to trigger emission of MCrS in trio trials.

Finally, the vibrational signals emitted during copulations could either prevent female movements or induce oviposition (Eberhard 1991). Another interesting hypothesis is that copulatory signals allow females to evaluate the mate after copulation has begun and choose whether use the sperm from successive males. This behavior has been described as cryptic female choice by Eberhard (1991) and seems to be widespread in insects and likely relevant in the evolution of genitalia as well.

\subsection{Conclusions and perspectives}

To conclude, $P$. spumarius communication is characterized by emission of vibrational signals, which have specific roles within the mating behavior.

The sexual behavior of $P$. spumarius shares similarities with several aspects of the stereotyped scheme known for other Auchenorrhyncha (Mazzoni et al. 2009b; De Groot et al. 2012) although many traits resemble more planthoppers (Fulgoromorpha) and sharpshooters (Cicadomorpha: Cicadellidae: Cicadellinae) than leafhoppers (Cicadomorpha: Cicadellidae other subfamilies). In particular, when individually placed on plants both males and females emitted spontaneous calling signals, like in many planthoppers (Ichikawa \& Ishii 1974; Booij 1982; Virant-Doberlet \& Žežlina 2007; Mazzoni et al. 2010) and in sharpshooters (Nieri et al. 2017), whereas in most leafhoppers (i.e. subfamilies Typhlocybinae and Deltocephalinae) only males call spontaneously while females emit replying signals (i.e. Mazzoni et al. 2009b; Derlink et al. 2014; Nieri \& Mazzoni 2018). However, if the MCS could increase the interest in mating of an immature female, the calling signals of $P$. spumarius would resemble the one described in cicadas and leafhoppers (Sueur 2002; Čokl \& Virant-Doberlet 2003; Mazzoni et al. 2014). Nonetheless, $P$. spumarius females emitted FCSs from different positions of the same plant, behavior observed also in H. obsoletus (Mazzoni et al. 2010). The similarities and differences in the behavioral pattern, however, could be a result of an ecological convergence rather than phylogeny divergence between these species. In fact, it is important to remember that P. spumarius, as well as $H$. obsoletus and 
$H$. vitripennis, is polyphagous and has an aggregated population structure.

Eventually, we consider possible the manipulation of $P$. spumarius by means of artificial playbacks and thus, future development of low environmental impact control practices. However, further research is needed to identify an efficient signal and the most suitable strategy for application in the field. One interesting approach could be to attract males into a trap using a specific vibrational signal, preferably before the adults move from the herbaceous vegetation to the olive tree canopy (Cornara et al. 2016). Since mating is achieved by exchange of signals between partners, it would be difficult to use the female response signal (FRsS) as directional cue to guide male into a trap. Nonetheless, in Halyomorpha halys the female calling signal was used with good efficacy even if male and female use to duet during the pair formation process (Mazzoni et al. 2017b). In this species, the male signal could increase the female motivation and induce acceptance; however, particularly motivated females likely do not require special "attention" and therefore males could reach them without emitting any signal, like in the case of some Apoidea species (Eickwort \& Ginsberg 1980). For this reason, it is worthy to test a $P$. spumarius female playback to lead nearby males into a trap, while another option is to use a pre-recorded male-female duet as attractive signal, exploiting a potential "satellite behavior", which was described in S. titanus, where the male could silently localize a duetting female (Mazzoni et al. 2009a; Virant-Doberlet et al. 2014). Finally, further experiments should be conducted to investigate the role of MMS and MCS and, indeed, playback trials should assess if the continuous transmission of a specific signal could disrupt an ongoing duet or cause repellence/stress in individuals that eventually would tend to leave the plants.

Author contribution statement: SA and VM conceived and designed the research. SA and ED conducted the experiments. SA, $\mathrm{ED}, \mathrm{PF}$ and VM analyzed the data. SA and VM wrote the manuscript. All authors read and approved the manuscript.

Acknowledgements: This work has been financially supported by European Union Horizon 2020 research and innovation program under grant agreements no. 727987 XF-ACTORS (Xylella fastidiosa Active Containment Through a multidisciplinary-Oriented Research Strategy). We acknowledge Marco Deromedi, Vincenzo Cavalieri, Flutra Lamaj, Nuray Baser and Michele Tucci for their precious help.

\section{Compliance with ethical standards}

Conflict of interest: There are no conflicts of interest involving the authors.

Animal rights statement: All applicable international, national, and/or institutional guidelines for the care and use of animals were followed.

Human rights statement: This article does not contain any studies with human participants performed by any of the authors.

\section{References}

Alexander, R. D. (1967). Acoustical communication in arthropods. Annual Review of Entomology, 12(1), 495-526. https://doi.org/ 10.1146/annurev.en.12.010167.002431

Anderson, M. J. (2008). A new method for non-parametric multivariate analysis of variance https://doi.org/10.1111/j.14429993.2001.01070.pp.x

Bailey, W. J. (2003). Insect duets: Underlying mechanisms and their evolution. Physiological Entomology, 28(3), 157-174. https://doi.org/10.1046/j.1365-3032.2003.00337.x

Bailey, W. J., Macleay, C., \& Gordon, T. (2006). Acoustic mimicry and disruptive alternative calling tactics in an Australian bushcricket (Caedicia; Phaneropterinae; Tettigoniidae; Orthoptera): Does mating influence male calling tactic? Physiological Entomology, 31(3), 201-210. https://doi.org/10.1111/j.13653032.2006.00501.x

Bodino, N., Cavalieri, V., Dongiovanni, C., Plazio, E., Saladini, M. A., Volani, S., ... Bosco, D. (2019). Phenology, seasonal abundance and stage-structure of spittlebug (Hemiptera: Aphrophoridae) populations in olive groves in Italy. Scientific Reports, 9(1), 1-17. https://doi.org/10.1038/s41598-019-54279-8

Booij, C. J. H. (1982). Biosystematics of the Muellerianella complex (Homoptera, Delphacidae), interspecific and geographic variation in acoustic behaviour. Zeitschrift für Tierpsychologie, 58(1), 31-52. https://doi.org/10.1111/j.1439-0310.1982.tb00307.x

Broughton, W. B. (1963). Method in bioacoustic terminology. In R. G. Busnel (Ed.), Acoustic behaviour of animals (p. 324). Amsterdam, London, New York: Elsevier Publishing.

Chmiel, S. M., \& Wilson, M. C. (1979). Estimation of the lower and upper developmental threshold temperatures and duration of the nymphal stages of the meadow spittlebug, Philaenus spumarius. Environmental Entomology, 8(4), 682-685. https://doi.org/ 10.1093/ee/8.4.682

Cocroft, R. B., \& Rodriguez, R. L. (2005). The behavioral ecology of insect vibrational communication. Bioscience, 55(4), 323334. https://doi.org/10.1641/0006-3568(2005)055[0323:TBEOI V]2.0.CO;2

Čokl, A., \& Virant-Doberlet, M. (2003). Communication with substrate-borne signals in small plant-dwelling insects. Annual Review of Entomology, 48(1), 29-50. https://doi.org/10.1146/ annurev.ento.48.091801.112605

Čokl, A., Virant-Doberlet, M., \& Stritih, N. (2000). The structure and function of songs emitted by southern green stink bugs from Brazil, Florida, Italy and Slovenia. Physiological Entomology, 25(2), 196-205. https://doi.org/10.1046/j.1365-3032.2000. 00187.x

Cornara, D., Bosco, D., \& Fereres, A. (2018a). Philaenus spumarius: When an old acquaintance becomes a new threat to European agriculture. Journal of Pest Science, 91(3), 957-972. https://doi. org/10.1007/s10340-018-0966-0

Cornara, D., Garzo, E., Morente, M., Moreno, A., Alba-Tercedor, J., \& Fereres, A. (2018b). EPG combined with micro-CT and video recording reveals new insights on the feeding behavior of Philaenus spumarius. PLoS One, 13(7), 1-20. https://doi. org/10.1371/journal.pone.0199154

Cornara, D., Morente, M., Markheiser, A., Bodino, N., Tsai, C.-W., Fereres, A., ... Lopes, J. R. S. (2019a). An overview on the worldwide vectors of Xylella fastidiosa. Entomologia Generalis, 39(34), 157-181. https://doi.org/10.1127/entomologia/2019/0811 
Cornara, D., Ripamonti, M., Morente, M., Garzo, E., Bosco, D., Moreno, A., \& Fereres, A. (2019b). Artificial diet delivery system for Philaenus spumarius, the European vector of Xylella fastidiosa. Journal of Applied Entomology, 143(8), 882-892. https://doi.org/10.1111/jen.12655

Cornara, D., Sicard, A., Zeilinger, A. R., Porcelli, F., Purcell, A. H., \& Almeida, R. P. P. (2016). Transmission of Xylella fastidiosa to grapevine by the meadow spittlebug. Phytopathology, 106(11), 1285-1290. https://doi.org/10.1094/PHYTO-05-16-0202-R

De Groot, M., Derlink, M., Pavlovčič, P., Prešern, J., Čokl, A., \& Virant-Doberlet, M. (2012). Duetting behaviour in the leafhopper Aphrodes makarovi (Hemiptera: Cicadellidae). Journal of Insect Behavior, 25(5), 419-440. https://doi.org/10.1007/ s10905-011-9304-6

Denancé, N., Legendre, B., Briand, M., Olivier, V., De Boisseson, C., Poliakoff, F., \& Jacques, M. A. (2017). Several subspecies and sequence types are associated with the emergence of Xylella fastidiosa in natural settings in France. Plant Pathology, 66(7), 1054-1064. https://doi.org/10.1111/ppa.12695

Derlink, M., Pavlovčič, P., Stewart, A. J., \& Virant-Doberlet, M. (2014). Mate recognition in duetting species: The role of male and female vibrational signals. Animal Behaviour, 90, 181-193. https://doi.org/10.1016/j.anbehav.2014.01.023

Eberhard, W. G. (1991). Copulatory courtship and cryptic female choice in insects. Biological Reviews of the Cambridge Philosophical Society, 66(1), 1-31. https://doi.org/10.1111/ j.1469-185X.1991.tb01133.x

Eickwort, G. C., \& Ginsberg, H. S. (1980). Foraging and mating behavior in Apoidea. Annual Review of Entomology, 25(1), 421-446. https://doi.org/10.1146/annurev.en.25.010180.002225

Endler, J. A. (1992). Signals, signal conditions, and the direction of evolution. American Naturalist, 139, 125-153. https://doi. org/10.1086/285308

Eriksson, A., Anfora, G., Lucchi, A., Lanzo, F., Virant-Doberlet, M., \& Mazzoni, V. (2012). Exploitation of insect vibrational signals reveals a new method of pest management. PLoS One, 7(3), e32954. https://doi.org/10.1371/journal.pone.0032954

Foster, S. P., \& Harris, M. O. (1997). Behavioral manipulation methods for insect pest-management. Annual Review of Entomology, 42(1), 123-146. https://doi.org/10.1146/annurev. ento.42.1.123

Gordon, S. D., Sandoval, N., Mazzoni, V., \& Krugner, R. (2017). Mating interference of glassy-winged sharpshooters, Homalodisca vitripennis. Entomologia Experimentalis et Applicata, 164(1), 27-34. https://doi.org/10.1111/eea.12594

Gwynne, D. T. (1987). Sex-biased predation and the risky matelocating behaviour of female tick-tock cicadas (Homoptera: Cicadidae). Animal Behaviour, 35(2), 571-576. https://doi. org/10.1016/S0003-3472(87)80283-X

Halkka, O., \& Halkka, L. (1990), Population genetics of the polymorphic meadow spittlebug, Philaenus spumarius (L.). Evolutionary biology (USA) 24: 149-91

Halkka, O., Halkka, L., Raatikainen, M., \& Hovinen, R. (1973). The genetic basis of balanced polymorphism in Philaenus (Homoptera). Hereditas, 74(1), 69-80. https://doi.org/10.1111/ j.1601-5223.1973.tb01105.x

Hartman, E., Rohde, B., Lujo, S., Dixon, M., McNeill, S., \& Mankin, R. W. (2017). Behavioral responses of male Diaphorina citri (Hemiptera: Liviidae) to mating communication signals from vibration traps in citrus (Sapindales: Rutaceae) trees. The
Florida Entomologist, 100(4), 767-771. https://doi.org/ 10.1653/024.100.0425

Heady, S. E., Nault, L. R., Shambaugh, G. F., \& Fairchild, L. (1986). Acoustic and mating behavior of Dalbulus leaf hoppers (Homoptera: Cicadellidae). Annals of the Entomological Society of America, 79(4), 727-736. https://doi.org/10.1093/aesa/ 79.4.727

Hoch, H., \& Howarth, F. G. (1993). Evolutionary dynamics of behavioral divergence among populations of the Hawaiian cavedwelling planthopper Oliarus polyphemus (Homoptera: Fulgoroidea: Cixiidae). Pacific Science, 47(4), 303-318.

Ichikawa, T., \& Ishii, S. (1974). Mating signal of the brown planthopper, Nilaparvata lugens Stål (Homoptera: Delphacidae): vibration of the substrate. Applied Entomology and Zoology, 9(3), 196-198. https://doi.org/10.1303/aez.9.196

Krugner, R. (2010). Differential reproductive maturity between geographically separated populations of Homalodisca vitripennis (Germar) in California. Crop Protection (Guildford, Surrey), 29(12), 1521-1528.https://doi.org/10.1016/j.cropro.2010.08.014

Krugner, R., \& Gordon, S. D. (2018). Mating disruption of Homalodisca vitripennis (Germar) (Hemiptera: Cicadellidae) by playback of vibrational signals in vineyard trellis. Pest Management Science, 74(9), 2013-2019. https://doi.org/ $10.1002 /$ ps.4930

Kuhelj, A., De Groot, M., Pajk, F., Simčič, T., \& Virant-Doberlet, M. (2015). Energetic cost of vibrational signalling in a leafhopper. Behavioral Ecology and Sociobiology, 69(5), 815-828. https://doi.org/10.1007/s00265-015-1898-9

Markheiser, A., Cornara, D., Fereres, A., \& Maixner, M. (2020). Analysis of vector behavior as a tool to predict Xylella fastidiosa patterns of spread. Entomologia Generalis, 40(1), 1-13. https://doi.org/10.1127/entomologia/2019/0841

Maryańska-Nadachowska, A., Kajtoch, Ł., \& Lachowska, D. (2012). Genetic diversity of Philaenus spumarius and P. tesselatus (Hemiptera, Aphrophoridae): Implications for evolution and taxonomy. Systematic Entomology, 37(1), 55-64. https://doi. org/10.1111/j.1365-3113.2011.00592.x

Mazzoni, V., Eriksson, A., Anfora, G., Lucchi, A., \& VirantDoberlet, M. (2014). Active Space and the Role of Amplitude in Plant-Borne Vibrational Communication. In R. Cocroft, M. Gogala, P. Hill, \& A. Wessel (Eds.), Studying Vibrational Communication. Animal Signals and Communication (Vol. 3). Berlin, Heidelberg: Springer; https://doi.org/10.1007/978-3662-43607-3_8

Mazzoni, V., Gordon, S. D., Nieri, R., \& Krugner, R. (2017a). Design of a candidate vibrational signal for mating disruption against the glassy-winged sharpshooter, Homalodisca vitripennis. Pest Management Science, 73(11), 2328-2333. https://doi. org/10.1002/ps.4619

Mazzoni, V., Lucchi, A., Čokl, A., Prešern, J., \& Virant-Doberlet, M. (2009a). Disruption of the reproductive behaviour of Scaphoideus titanus by playback of vibrational signals. Entomologia Experimentalis et Applicata, 133(2), 174-185. https://doi.org/10.1111/j.1570-7458.2009.00911.x

Mazzoni, V., Lucchi, A., Ioriatti, C., Virant-Doberlet, M., \& Anfora, A. (2010). Mating behavior of Hyalesthes obsoletus (Hemiptera: Cixiidae). Annals of the Entomological Society of America, 103(5), 813-822. https://doi.org/10.1603/AN09145

Mazzoni, V., Polajnar, J., Baldini, M., Rossi Stacconi, M. V., Anfora, G., Guidetti, R., \& Maistrello, L. (2017b). Use of sub- 
strate-borne vibrational signals to attract the Brown Marmorated Stink Bug, Halyomorpha halys. Journal of Pest Science, 90(4), 1219-1229. https://doi.org/10.1007/s10340-017-0862-z

Mazzoni, V., Prešern, J., Lucchi, A., \& Virant-Doberlet, M. (2009b). Reproductive strategy of the Nearctic leafhopper Scaphoideus titanus Ball(Hemiptera: Cicadellidae). Bulletin of Entomological Research, 99(4), 401-413. https://doi.org/10.1017/S00074853 08006408

Michelsen, A., Fink, F., Gogala, M., \& Traue, D. (1982). Plants as transmission channels for insect vibrational songs. Behavioral Ecology and Sociobiology, 11(4), 269-281. https://doi.org/ 10.1007/BF00299304

Miranda, X. (2006). Substrate-borne signal repertoire and courtship jamming by adults of Ennya chrysura (Hemiptera: Membracidae). Annals of the Entomological Society of America, 99(2), 374-386. https://doi.org/10.1603/0013-8746(2006)099 [0374:SSRACJ]2.0.CO;2

Morente, M., Cornara, D., Moreno, A., \& Fereres, A. (2018). Continuous indoor rearing of Philaenus spumarius, the main European vector of Xylella fastidiosa. Journal of Applied Entomology, 142(9), 901-904. https://doi.org/10.1111/jen. 12553

Nieri, R., \& Mazzoni, V. (2018). The reproductive strategy and the vibrational duet of the leafhopper Empoasca vitis. Insect Science, 25(5), 869-882. https://doi.org/10.1111/1744-7917. 12454

Nieri, R., Mazzoni, V., Gordon, S. D., \& Krugner, R. (2017). Mating behavior and vibrational mimicry in the glassy-winged sharpshooter, Homalodisca vitripennis. Journal of Pest Science, 90(3), 887-899. https://doi.org/10.1007/s10340-017-0840-5

Oksanen, J., Blanchet, F. G., Friendly, M., Kindt, R., Legendre, P., ..., Wagner, H. (2019). vegan: Community Ecology Package. $\mathrm{R}$ package version 2.5-5. https://CRAN.R-project.org/ package $=$ vegan

Olmo, D., Nieto, A., Adrover, F., Urbano, A., Beidas, O., Juan, A., ... Landa, B. B. (2017). First Detection of Xylella fastidiosa Infecting Cherry (Prunus avium) and Polygala myrtifolia plants, in Mallorca Island, Spain. Plant Disease, 101(10), 18201820. https://doi.org/10.1094/PDIS-04-17-0590-PDN

Pedigo, L. P., \& Rice, M. E. (2014). Entomology and pest management $\left(6^{\text {th }}\right.$ ed.). Waveland, Long Grove.

Pertot, I., Caffi, T., Rossi, V., Mugnai, L., Hoffmann, C., Grando, M. S., ... Anfora, G. (2017). A critical review of plant protection tools for reducing pesticide use on grapevine and new perspectives for the implementation of IPM in viticulture. Crop Protection (Guildford, Surrey), 97, 70-84. https://doi.org/ 10.1016/j.cropro.2016.11.025

Polajnar, J., Eriksson, A., Lucchi, A., Anfora, G., Virant-Doberlet, M., \& Mazzoni, V. (2015). Manipulating behaviour with substrate-borne vibrations - Potential for insect pest control. Pest Management Science, 71(1), 15-23. https://doi.org/10.1002/ ps. 3848

Polajnar, J., Eriksson, A., Rossi Stacconi, M. V., Lucchi, A., Anfora, G., Virant-Doberlet, M., \& Mazzoni, V. (2014). The process of pair formation mediated by substrate-borne vibrations in a small insect. Behavioural Processes, 107, 68-78. https://doi.org/ 10.1016/j.beproc.2014.07.013

Polajnar, J., Eriksson, A., Virant-Doberlet, M., \& Mazzoni, V. (2016). Mating disruption of a grapevine pest using mechanical vibrations: From laboratory to the field. Journal of Pest Science, 89(4), 909-921. https://doi.org/10.1007/s10340-015-0726-3
R Core Team (2019). R: A language and environment for statistical computing. R Foundation for Statistical Computing, Vienna, Austria. https://www.R-project.org/

Robertson, A., \& Gibbs, A. J. (1937). Spermatogenesis and fertilization in Philaenus spumarius Fallen. The Journal of Tropical Medicine and Hygiene, 40, 257-262.

Rodrigues, A. S., Silva, S. E., Marabuto, E., Silva, D. N., Wilson, M. R., Thompson, V., ... Seabra, D. G. (2014). New mitochondrial and nuclear evidences support recent demographic expansion and an atypical phylogeographic pattern in the spittlebug Philaenus spumarius (Hemiptera, Aphrophoridae). PLoS One, 9(6), e98375. https://doi.org/10.1371/journal.pone.0098375

Santoiemma, G., Tamburini, G., Sanna, F., Mori, N., \& Marini, L. (2019). Landscape composition predicts the distribution of Philaenus spumarius, vector of Xylella fastidiosa, in olive groves. Journal of Pest Science, 92(3), 1101-1109. https://doi. org/10.1007/s10340-019-01095-8

Saponari, M., Boscia, D., Altamura, G., Loconsole, G., Zicca, S., D'Attoma, G., ... Martelli, G. P. (2017). Isolation and pathogenicity of Xylella fastidiosa associated to the olive quick decline syndrome in southern Italy. Scientific Reports, 7(1), 17723. https://doi.org/10.1038/s41598-017-17957-z

Saponari, M., Loconsole, G., Cornara, D., Yokomi, R. K., De Stradis, A., Boscia, D., ... Porcelli, F. (2014). Infectivity and transmission of Xylella fastidiosa by Philaenus spumarius (Hemiptera: Aphrophoridae) in Apulia, Italy. Journal of Economic Entomology, 107(4), 1316-1319. https://doi.org/ $10.1603 / \mathrm{EC} 14142$

Soetaert, K. (2017). plot3D: Plotting Multi-Dimensional Data. R package version 1.1.1. https:/CRAN.R-project.org/package= plot3D

Stewart, A. J. A., \& Lees, D. R. (1996). The colour/pattern polymorphism of Philaenus spumarius (L.) (Homoptera: Cercopidae) in England and Wales. Philosophical Transactions of the Royal Society of London. Series B, Biological Sciences, 351(1335), 69-89. https://doi.org/10.1098/rstb.1996.0005

Sueur, J. (2002). Cicada acoustic communication: potential sound partitioning in a multispecies community from Mexico (Hemiptera: Cicadomorpha: Cicadidae). Biological Journal of the Linnean Society. Linnean Society of London, 75(3), 379394. https://doi.org/10.1111/j.1095-8312.2002.tb02079.x

Tishechkin, D. Y. (2003). Vibrational communication in Cercopoidea and Fulgoroidea (Homoptera: Cicadina) with notes on classification of higher taxa. Russian Entomological Journal, 12(2), 127-181.

Virant-Doberlet, M., \& Žežlina, I. (2007). Vibrational communication of Metcalfa pruinosa (Hemiptera: Fulgoroidea: Flatidae). Annals of the Entomological Society of America, 100(1), 73-82. https://doi.org/10.1603/0013-8746(2007)100[73:VCOMPH]2.0 .CO; 2

Virant-Doberlet, M., Mazzoni, V., de Groot, M., Polajnar, J., Lucchi, A., Symondson, W. O. C., \& Čokl, A. (2014). Vibrational Communication Networks: Eavesdropping and Biotic Noise. In R. Cocroft, M. Gogala, P. Hill, \& A. Wessel (Eds.), Studying Vibrational Communication. Animal Signals and Communication (Vol. 3). Berlin, Heidelberg: Springer; https://doi.org/10.1007/ 978-3-662-43607-3_7

Weaver, C. R., \& King, D. R. (1954). Meadow spittlebug, Philaenus leucophthalmus (L.). Research Bulletin, 741.

Wickham, H. (2016). ggplot2: Elegant Graphics for Data Analysis. Springer-Verlag New York 
Wickham, H. (2017). tidyverse: Easily Install and Load the 'Tidyverse'. R package version 1.2.1. https://CRAN.R-project. org/package $=$ tidyverse

Witsack, W. (1973). Experimental and ecological investigations on forms of dormancy in homoptera-cicadina (Auchenorrhyncha). On ovarian parapause and obligatory embryonic diapause in Philaenus spumarius (L.) (Aphrophoridae). Zoologische Jahrbucher. Abteilung fur Systematik, Ökologie und Geographie der Tiere, 100, 517-562.

Yurtsever, S. (2001). Multiple paternity in the meadow spittlebug Philaenus spumarius (L.) (Homoptera: Cercopidae). Acta Zoologica Cracoviensia, 44(3), 173-84

Zar, J. H. (1999). Biostatistical analysis (p. 663).
The pdf version (Adobe JavaScript must be enabled) of this paper includes an electronic supplement: Audiosupplement

Manuscript received: 24 December 2019

Revisions requested: 17 February 2020

Modified version received: 28 February 2020

Accepted: 10 May 2020 